Revista Destaques Acadêmicos, Lajeado, v. 11, n. 1, 2019. ISSN 2176-3070

DOI: http://dx.doi.org/10.22410/issn.2176-3070.v11i1a2019.2136 http://www.univates.br/revistas

\title{
CARACTERÍSTICAS DO PROCESSO DE COMPRA PELA INTERNET REALIZADA POR ESTUDANTES UNIVERSITÁRIOS
}

\author{
Willian Emilio Pivatto ${ }^{1}$, Samuel Martim de Conto ${ }^{2}$, Gabriel Machado Braido ${ }^{3}$
}

Resumo: Devido ao desenvolvimento da tecnologia e dos meios de transmissão das informações, o comércio eletrônico ou e-commerce na última década cresceu significativamente. O objetivo deste estudo é caracterizar o comportamento de compra pela internet dos alunos da Universidade do Vale do Taquari - Univates, localizada no município de Lajeado - RS. Para alcançar esse objetivo estabelecido, foi realizada inicialmente a pesquisa qualitativa exploratória, junto a 10 consumidores que habitualmente compram pela internet. Posteriormente, utilizando os resultados dessa etapa, foi aplicado o questionário e respondido por 310 alunos da Instituição. Tratou-se de uma pesquisa quantitativa descritiva, com a finalidade de caracterizar o perfil desses estudantes, a frequência com que realizam compras pela internet, seu valor médio, os principais fatores que influenciam no momento de compra, a categoria mais procurada e também a forma de pagamento utilizada com mais frequência. Após a realização da pesquisa, os dados foram analisados estatisticamente e dentre os principais resultados encontrados, destaca-se o preço dos produtos e serviços oferecidos como fator principal que leva os alunos a comprarem pela internet. Além disso, a maioria dos respondentes realiza pesquisas de preços e produtos nas lojas físicas, antes de efetuar uma aquisição virtual.

Palavras-chave: Comportamento. Comércio eletrônico. Pesquisa. Internet.

\section{INTRODUÇÃO}

O comércio sempre fez parte da história da humanidade e já foi encarado como mercado de trocas, em que as pessoas negociavam produtos que

1 Graduado em Administração pela Universidade do Vale do Taquari - Univates. E-mail: willian69_pivatto@yahoo.com.br

2 Doutor em Administração e professor da Universidade do Vale do Taquari - Univates. E-mail: samuelc@univates.br

3 Doutorando em Administração e coordenador do curso de Administração da Universidade do Vale do Taquari - Univates. E-mail: gabrielb@univates.br 
produziam em excesso por outros produtos os quais não possuíam, conhecido por escambo. É o comércio tradicional que continua a se basear na troca de bens e serviços para satisfazer as necessidades do homem, no qual o objetivo ainda é o mesmo.

A internet tem apenas duas décadas de existência no mundo empresarial, se levar como referência o ano de 1989, quando surgiu o primeiro provedor comercial do mundo, o The World, nos Estados Unidos. Essa tecnologia propiciou a evolução rápida do comércio, tornando-se parte integrante dele. A comercialização pela internet teve início em 1994.

Diante do crescimento da implantação do e-commerce nas transações comerciais e de negócios, faz-se necessário abordar os aspectos de mudanças nas relações comerciais ao focalizar suas perspectivas e tipificações. O choque gerado por esse novo meio de comércio tem causado impactos sobre a economia, bem como suas implicações legais e expectativas futuras.

O e-commerce é um canal de vendas moderno e fácil, não envolve grandes investimentos de recursos ou de pessoal e pode ser acessado com um navegador da web através do meio eletrônico mais comum atualmente: a internet.

O crescimento de compras pela internet é constante. O consumidor está cada vez mais atento aos produtos, às promoções, aos preços e nas demais ofertas que as empresas utilizam por meio dessa. Através dessa conexão, é possível que os consumidores recebam produtos de boa qualidade na comodidade de sua residência, antes mesmo de estarem disponíveis nas lojas físicas de sua região.

Diante esse contexto, este trabalho teve o propósito de responder à seguinte questão: "como se caracteriza o comportamento dos alunos da Univates, no que se refere a compras pela internet?"

Para tanto, este estudo teve como objetivo geral caracterizar o comportamento de compra pela internet dos alunos da Univates. Para isso, foi necessário primeiramente caracterizar o perfil dos alunos consumidores da Instituição, identificar a frequência com que os alunos realizam compras pela internet e o valor médio dessas compras, apresentando ainda os principais fatores que influenciam no momento da escolha de um determinado produto e identificando a forma de pagamento que o aluno utiliza com mais frequência.

O estudo foi desenvolvido com alunos de diferentes áreas e cursos da Instituição, localizada na cidade de Lajeado - RS. Foi elaborado um questionário com questões objetivas, sendo essas aplicadas no semestre 2017/A, tendo 310 respondentes. Para a fundamentação do estudo, foram utilizados bibliografias e artigos acadêmicos que abordam a temática do estudo como: comércio eletrônico, marketing, internet, entre outros. Primeiramente, o estudo foi de caráter exploratório, e posteriormente de caráter descritivo, onde os resultados foram analisados e serviram de subsídio para conclusões. 
Dessa forma, este estudo se justifica na importância em identificar o comportamento de compra pela internet dos alunos de uma universidade. Por meio de uma pesquisa de caráter não probabilístico, buscou-se apresentar se os alunos estão ou não conectados atualmente ao comércio eletrônico e até mesmo caracterizar o seu perfil empreendedor nessa área. Tornou-se importante entender o comportamento dos universitários mediante as compras nessa modalidade oferecida e mais conveniente.

\section{FUNDAMENTAÇÃO TEÓRICA}

\subsection{Comércio}

O comércio surgiu por meio de trocas, sendo que alguns grupos trocavam suas mercadorias por outras diferentes, sem envolvimento de moeda. Portanto, a ideia de comércio é a realização de trocas de um determinado produto ou serviço, sendo que na sociedade de hoje o dinheiro é principal moeda de troca por produtos e serviços (SILVA, 2016).

De acordo com Veríssimo (2004, texto digital), o desenvolvimento do planeta deu-se a partir do comércio. Logo que o homem deixou de ser nômade e firmou-se nas comunidades, existia o mercado, lugar em que ocorriam as compras e vendas de bens através do escambo. Para conquistar novos mercados, nos séculos XII e XIV, os fenícios fabricaram navios e se projetaram nas águas do mar.

Em complemento, acrescenta que na Idade Média os portugueses da mesma forma se arriscaram em viagens pelos oceanos, na busca de novos artefatos. Necessariamente a tecnologia acabou sendo desenvolvida pela sociedade da época, conquistando assim novos horizontes (VERÍSSIMO, 2004, texto digital).

\subsection{Comércio eletrônico}

O e-commerce através de meios eletrônicos possibilita a realização de operações com o propósito de trocar bens ou serviços entre dois ou mais componentes. O processo de compra e venda de bens, serviços e informações por meios digitais é possível através do comércio eletrônico. Foi no início dos anos 1990 que ocorreu o surgimento desse modelo de comércio. Consequentemente, para Turban e King (2004), nesse período, mediante as tecnologias de rede, softwares e outras, o mercado acendeu e teve um significativo crescimento.

Para Albertin (2000), o comércio eletrônico é a realização integral da cadeia de valores do sistema de um negócio em um ambiente eletrônico, através da utilização acentuada de tecnologias da comunicação e de informação, com o propósito de atender objetivos de negócio de forma total. 
Conforme Turban, Rainer e Potter (2003), na lista a seguir encontram-se os principais espaços onde atuam o comércio eletrônico:

a) comércio colaborativo: (e-commerce):é o tipo de comércio eletrônico o qual existe colaboração eletrônica entre os parceiros de negócios. É utilizado de forma frequente por parceiros de negócios de suprimentos;

b) business-to-business (B2B): esse tipo de comércio eletrônico envolve duas ou mais empresas que realizam transações ou colaboram de forma eletrônica;

c) business-to-consumers (B2C): é o tipo de comércio efetuado diretamente entre a empresa produtora, vendedora ou prestadora de serviços e o consumidor final;

d) consumers-to-business (C2B): esse tipo de comércio eletrônico é propriamente a relação entre consumidores e empresas. Nesse formato elas se adequam ao consumidor, oferecendo a melhor proposta;

e) consumer-to-consumer ( $\mathrm{C} 2 \mathrm{C})$ : é o tipo de comércio eletrônico que envolve transações entre dois ou mais indivíduos;

f) comércio intra-empresas (intra-organizacional): nesse tipo de comércio eletrônico uma organização utiliza internamente o CE com o intuito de melhorar suas operações. Como exemplo é conhecido como o CE B2E (business-to-employees), onde uma organização oferta produtos ou serviços aos seus colaboradores;

g) governo-para-cidadãos (G2C): é o tipo de comércio eletrônico onde uma entidade do governo, no caso uma unidade, oferta serviços aos seus cidadãos utilizando as tecnologias do comércio eletrônico. As unidades do governo conseguem realizar negócios com demais unidades, e da mesma forma com empresas;

h) comércio móvel (m-commerce): esse tipo de comércio eletrônico é realizado em um ambiente sem fio, através de celulares, smartphones ou tablets, ambos devidamente com conexão à internet, para assim poder efetuar a compra desejada;

Conforme informações publicadas por Terzoni (2015, texto digital), a rede social Facebook tem ganhado um grande espaço no comércio eletrônico e através desse meio é esperado um enorme crescimento para os próximos anos.

i) Facebook-commerce ou e-commerce: esse é o tipo de comércio eletrônico mais atual do momento, e a cada ano cresce mais. É uma loja virtual construída dentro do ambiente do Facebook, onde o usuário utiliza o canal para divulgação, mídia e venda do seu e-commerce.

Laudon e Laudon (2007) acrescentam que indispensavelmente podese classificar os três principais tipos de categorias, conforme as operações 
do comércio eletrônico. Sendo assim, o comércio eletrônico tem as seguintes categorias: empresa-consumidor, empresa-empresa e consumidor-consumidor.

\subsection{Relação do consumidor com a internet}

Para Shet et al. (2002), o consumidor on-line tende a ser mais exigente e ter mais tempo para as compras, uma vez que essas lojas podem ser acessadas no espaço virtual em qualquer lugar e a qualquer hora, bastando estar conectada à rede. Mas ainda existem alguns obstáculos, o mais importante expoente de segurança de dados, o que significa que os consumidores estão mais desconfiados em relação a esse tipo de atividade. Os autores acrescentam que o e-business, ou seja, os negócios on-line, vieram para preencher a necessidade da empresa de se relacionar de forma direta com o cliente, economizando assim espaço físico e tempo.

Conforme Mattos et al. (2011), a era eletrônica aumentou significativamente o crescimento da loja sem afetar os consumidores que podem receber os seus bens pelos Correios, na compra pela televisão, na internet ou por telefone. E, muitas vezes, sem taxa de entrega, dependendo dos itens, do valor e quantidade de uma ou mais compras.

As lojas virtuais estão sendo muito procuradas pelos consumidores, deixando de lado as lojas físicas. O comprador está mais atento, econômico e exigente.

\subsection{Decisão de compra}

No processo de decisão de compra, para Tapscott (2010), existem cinco tipos de ações que são realizadas durante esse processo; a) iniciador: a pessoa que se propõe a comprar o produto e contém informações que cooperaram na decisão de compra; b) influenciador: é o ponto de vista da pessoa diretamente que influencia as decisões de compras; c) decisionmaker: a pessoa que realmente decide o que comprar, como comprar, quando e onde comprar; d) comprador: a pessoa que é o preço de compra real decidido anteriormente; e) usuário: é a pessoa que vai consumir o que foi comprado.

Complementando, Hoffmann e Novak (2002) destacam que o processo de decisão de compra passa por incentivos não apenas demográficos e de marketing, pois são também influenciados por elementos ambientais e situacionais. Segundo o autor, existe uma divisão desse processo em três estágios interligados:

a) estágio de Input: estímulos de marketing e os fatores do ambiente interferem na decisão de compra do consumidor;

b) estágio de decisão: refere-se à forma de como os consumidores tomam as suas decisões; 
c) estágio de Output: trata-se da escolha de uma alternativa provável, nomeada também de avaliação de alternativas.

\subsection{O perfil do comprador on-line}

Para Cobra (2006), o consumidor on-line se define por uma nomenclatura para o e-consumidor. Essa nomenclatura distingue claramente o consumidor a fazer suas compras por meio da internet, que anteriormente eram realizadas no varejo tradicional. É importante ressaltar que essas duas classificações de consumidores são aplicadas a um indivíduo, como eles se relacionam com a capacidade de comprá-los.

Ainda segundo Cobra (2006), podem ser destacados quatro critérios diferentes para segmentar mercados consumidores:

a) critérios geograficamente, demograficamente, socialmente e economicamente, sendo o primeiro referente aos tipos de região (clima e relevo), o segundo referente ao gênero, idade e tamanho da família, e o terceiro e quarto critério referente a renda, educação e religião;

b) critérios de personalidade e estilo de vida, como atividades, interesses, valores;

c) critérios comportamentais para o produto/serviço, onde esse comportamento refere-se à quantidade de uso de lealdade à marca;

d) critérios de atitude psicológica sobre o produto/serviço.

Os consumidores devem ser estudados sob a ótica demográfica e psicográfica. Essa combinação ocorre em três dimensões, que de acordo com Laudon e Laudon (2007) são: receita (alta ou baixa), atitudes a tecnologia (otimistas ou pessimistas) e principal motivação (carreira, família e entretenimento).

Esses extratos são tomados de subgrupos de consumidores que estão agrupados por diferentes perfis, sendo separados por aqueles com rendimentos mais altos e maior otimismo sobre a tecnologia. Aqueles que usam a rede com a carreira principal são acelerados, os que possuem uma renda alta, otimismo e se motivam quando as necessidades da família são a favor da nova era (RIZZO, 2001). Ou seja, o perfil do comprador on-line é distinto entre todas as faixas etárias. E a internet é uma grande influenciadora em boa parte dessas compras.

\subsection{Visão geral do marketing}

Segundo Cordeiro (2006), o marketing se define como a análise do comportamento do consumidor na busca da satisfação de suas vontades e necessidades por meio de ações, bens e serviços, sendo ele fascinado e assim os adquirindo. 
No decorrer do tempo, com o grande avanço tecnológico, o marketing alterou o seu modelo. De acordo com Mckenna (1992), a visão de que o marketing era apenas vender foi excluída, dando lugar a um novo paradigma que traz um marketing baseado em conhecimento e em experiência.

Conforme Las Casas (2010), é de responsabilidade das empresas ter um bom departamento de marketing e com formas diferenciadas de pensamento. Estão constantemente buscando o melhor conhecimento de seus clientes, usufruindo de tecnologias para atendê-los com excelência e por fim, buscando entendê-los economicamente. Acrescenta ainda que todos os produtos ou serviços oferecidos no mercado têm como foco principal o consumidor.

Para Kotler e Keller (2006), as melhores ideias se encontram no departamento de marketing de uma empresa. Por meio de boas condutas, é possível promover a mesma para o mercado competitivo. Qualquer departamento pode tratar bem ou mal um cliente e isso terá influência direta em seu futuro interesse na empresa. Ter um gestor de marketing que saiba se relacionar com seus clientes é um fator significativo para o sucesso do negócio.

\section{PROCEDIMENTOS METODOLÓGICOS}

A pesquisa ocorreu em duas etapas, sendo a primeira qualitativa/ exploratória e a segunda quantitativa/descritiva.

Conforme Martins e Laugeni (2005), a pesquisa qualitativa é um método de investigação empregado em muitas disciplinas acadêmicas diferentes, incluindo nas ciências sociais e ciências naturais, mas também em pesquisa de mercado, nos negócios, e outros contextos, incluindo demonstrações de serviços por organizações sem fins lucrativos. Complementando, Roesch (2005), menciona que a pesquisa qualitativa procura a melhora da efetividade de um plano ou programa, e seus métodos de coleta e análises dos dados são mais favoráveis para uma fase de pesquisa exploratória.

Conforme Gil (2007), a pesquisa exploratória busca possibilitar uma maior familiaridade com o problema, transformando-o em mais explícito e oportunizando a criação de hipóteses. Envolve normalmente o levantamento bibliográfico, entrevistas com pessoas e análises de exemplos. Segundo Malhotra (2006), entrevistas individuais em profundidade possibilitam uma enorme sondagem de cada entrevistado, pois nesse modelo de pesquisa a amostragem é menor e a metodologia de pesquisa não é estruturada, proporcionando uma visão melhor e um bom entendimento do contexto do problema.

Com isso, na primeira etapa do estudo, foram realizadas 10 entrevistas em profundidade, com consumidores que possuem o hábito de adquirir produtos ou serviços pela internet e possibilitando explorar o tema de estudo. Essas entrevistas foram gravadas e posteriormente transcritas. O resultado, em conjunto com o referencial teórico, foi possível a elaboração do questionário da etapa seguinte. 
De acordo com Mattar (2001), a pesquisa quantitativa procura validar hipóteses através do aproveitamento de dados estruturados, estatísticos, com análise de um amplo número de casos representativos, sugerindo um curso final da ação. Essa pesquisa quantifica os dados e generaliza os resultados da amostra para os interessados. Ainda de acordo com Gil (2007), as variáveis podem ser quantificadas e agrupadas, é viável analisá-las estatisticamente com o uso de correlações e outros métodos estatísticos.

Para Gil (2007), o principal objetivo de uma pesquisa descritiva é a descrição das características de determinado fenômeno ou população. Acrescenta o autor que as pesquisas descritivas visam estabelecer relações entre variáveis, ou ainda, algumas dessas pesquisas vão além da simples identificação e planejam definir a natureza dessa relação.

A segunda etapa da pesquisa, foi aplicado um questionário aos estudantes do semestre 2017/A da Univates. A pesquisa constituiu-se por 20 questões fechadas em sua maior parte, sendo essas preenchidas sem a presença do pesquisador. Uma parte foi aplicada por um dos professores do curso, em sala de aula, e a outra foi aplicada via Google Forms, através da internet.

Em relação à população do estudo (MARCONI e LAKATOS, 2001), em 2017 a Instituição contava com 13.595 alunos matriculados nos mais diversos níveis e tipos de cursos. Dessa população foi definida uma amostra nãoprobabilística por conveniência de 310 alunos.

O pré-teste, que segundo Malhotra (2001) trata-se de uma avaliação do questionário em uma pequena amostra dos entrevistados, foi realizado com 10 pessoas, sendo que, os resultados demonstraram a não necessidade de ajustes.

A análise dos dados coletados foi dividida em dois momentos: no primeiro foram analisados os dados provenientes das entrevistas em profundidade, por meio da análise de conteúdo, e após analisou-se os dados provenientes da aplicação do questionário, por meio da estatística descritiva.

A principal limitação metodológica diz respeito ao tipo de amostragem utilizada (não-probabilística por conveniência), a qual não pode ser extrapolada para o seu universo, sendo válida única e exclusivamente sua análise e conclusões aos respondentes.

\section{APRESENTAÇÃO E ANÁLISE DOS RESULTADOS}

\subsection{Apresentação dos resultados das entrevistas em profundidade}

As entrevistas em profundidade foram realizadas por meio de um roteiro contendo nove questões e aplicada com 10 pessoas, sendo cinco do sexo feminino e outras cinco do sexo masculino. Essas pessoas adquirem regularmente produtos e serviços através do comércio eletrônico. 
A média de idade dos entrevistados foi de 27,8 anos. Quanto à escolaridade, $70 \%$ possuíam curso superior completo, $20 \%$ possuíam curso técnico completo e $10 \%$ curso superior incompleto. Em relação ao estado civil das pessoas, $90 \%$ afirmam ser solteiros e $10 \%$ casados.

Em relação às compras virtuais, o aspecto que mais é levado em consideração na hora de realizar a compra virtual é o menor preço (sendo citado por $100 \%$ dos entrevistados). Outros aspectos também foram mencionados como a variedade dos produtos, a facilidade de compra, a entrega, o prazo para pagamento e a credibilidade do vendedor.

Quanto à regularidade de aquisições pela internet, 70\% das pessoas entrevistadas declararam comprar mensalmente. Em relação ao gasto médio das compras virtuais, a média de gasto foi de $\mathrm{R} \$ 394,44$.

A respeito dos principais motivos que fazem essas pessoas a optar pelo produto da sua escolha no momento da compra, a qualidade do produto ou serviço foi a mais votada, seguida da marca, preço, custo benefício, necessidade, estética do produto, a credibilidade do vendedor, o frete, a confiabilidade do site, a durabilidade e maiores informações do produto desejado.

Em relação à forma de pagamento mais utilizada pelos entrevistados, $70 \%$ informam usar o cartão de crédito para realizar o pagamento, pois oferece maior comodidade, praticidade e opção de parcelamento das compras. Outros $30 \%$ optam pelo boleto bancário, por questões de segurança e maior sigilo de dados bancários, além de maiores descontos pelo fato de ser pagamento à vista.

\subsection{Apresentação dos resultados do levantamento}

De acordo com o questionário respondido por 310 alunos da Instituição, apurou-se que $91,93 \%$ do total dos entrevistados realiza compras pela internet.

Caracterizando o perfil dos alunos consumidores e não consumidores do e-commerce, conforme resultados obtidos através dessa pesquisa, 57,74\% dos respondentes eram do sexo feminino e $42,26 \%$ do sexo masculino. Sobre a idade dos entrevistados, 32,90\% tinham entre 16 e 21 anos, 40,65\% idade entre 22 e 27 anos, $13,87 \%$ entre 28 e 33 anos, 7,42\% entre 34 e 39 anos e por fim, 5,16\% tinham idade acima dos 40 anos.

Segundo a pesquisa, tratando-se do estado civil dos estudantes, a maioria era solteira $(75,48 \%)$. Outros $11,61 \%$ tinham uma união estável. Os casados representavam $11,30 \%$. Desquitados ou divorciados constituíam os demais 1,61\%. A respeito da escolaridade destes, 67,42\% revelaram ter Ensino Superior incompleto. Outros 22,58\% assumiram ter o Ensino Superior completo. Ainda 4,84\% possuíam Pós-graduação, 0,97\% tinham Mestrado, 0,65\% tinham Doutorado e os que responderam "Outro" correspondiam a 3,55\%.

A importância de analisar os mais diversos perfis são apontados por Rizzo (2001) e Cobra (2006), mencionando o critério demográfico para 
segmentação dos mercados consumidores, podendo ser quanto ao gênero, à idade, ao tamanho da família e à renda.

Com relação à renda mensal individual, constatou-se que 20,97\% recebem até um salário mínimo. Os que recebem entre dois a três salários mínimos somaram $61,94 \%$ do total. Outros $12,58 \%$ recebiam entre quatro e seis salários mínimos, 2,58\% recebiam entre sete e nove salários mínimos, e somente 1,94\% recebiam acima de dez salários mínimos.

Quanto ao número de filhos, a maioria dos entrevistados declarou não ter nenhum filho, correspondendo a $86,13 \%$ do total. Assumiram ter um filho, 9,68\% dos respondentes. Outros 2,90\% possuíam dois filhos. Asseguram possuir três filhos 0,97\%, e os que possuíam mais de três filhos eram $0,32 \%$.

Para identificar a frequência com que os alunos realizam compras pela internet e o valor médio dessas compras, procurou-se saber com qual periodicidade uma compra é realizada. Os resultados apontaram que 34,19\% compram trimestralmente, $31,94 \%$ afirmaram comprar mensalmente, $21,94 \%$ declararam comprar anualmente e $6,45 \%$ nunca compraram pela internet, mas pretendem comprar um dia. Ainda, informaram que compram semanalmente $3,87 \%$ dos entrevistados e nunca compraram e não pretendem comprar 1,61\%.

Quanto ao valor médio gasto em cada compra virtual pelos alunos, no valor de até $\mathrm{R} \$ 100,00$, foi apontada por $14,84 \%$ dos entrevistados. A maioria assume gastar entre $\mathrm{R} \$ 101,00$ e $\mathrm{R} \$ 200,00$, representando 33,55\% do total. Outros $19,35 \%$ gastam entre $R \$ 201,00$ e $R \$ 300,00$. Uma parcela de $9,35 \%$ gasta entre $R \$ 301,00$ e $R \$ 400,00$. Os que gastam entre $R \$ 401,00$ e $R$ \$ 500,00 são $3,55 \%$. Gastos acima de $\mathrm{R} \$ 501,00$ são realizados por $11,30 \%$ dos entrevistados.

Objetivando-se caracterizar o comportamento de compra pela internet dos alunos da Instituição, buscou-se saber quais os fatores que levam os mesmos a comprar pela internet, e foram obtidos resultados apresentados na Tabela 1. Conforme o resultado apresentado, para 51,94\% dos respondentes o preço é o principal fator. Na sequência, $16,45 \%$ declararam ser a variedade o fator principal, seguido de facilidade de compra $(14,84 \%)$ e as condições de pagamento $(6,45 \%)$. A confiabilidade representou apenas $1,94 \%$ do total e a agilidade de entrega foi apontada por $0,32 \%$ dos respondentes.

Tabela 1 - Fatores que levam o consumidor a realizar compras pela internet

\begin{tabular}{l|c|c}
\hline \multicolumn{1}{c|}{ Fator } & $\mathbf{N}^{\mathbf{0}}$ de Citações & \% \\
\hline Preço & 161 & 51,94 \\
Variedade & 51 & 16,45 \\
Facilidade de compra & 46 & 14,84 \\
Não compro pela Internet & 25 & 8,07 \\
Condições de pagamento & 20 & 6,45 \\
Confiabilidade & 6 & 1,94 \\
Agilidade de entrega & 1 & 0,32 \\
\hline Total & 310 & 100,00 \\
\hline
\end{tabular}

Fonte: Resultado do levantamento (2017). 
Para conhecer melhor o costume dos alunos, foi questionado o motivo pelo qual habitualmente realizam compras pela internet, sendo que a maioria declarou que gosta de aproveitar as promoções, correspondendo a 50,65\% do total. Em seguida, 24,19\% afirmaram gostar de analisar as informações disponíveis sobre os produtos. Possuem pouco tempo livre $(11,94 \%)$ e possuem pouco tempo livre e gostam de analisar as informações foi apontado por 5,16\% dos respondentes.

De acordo com a pesquisa e dos dados coletados, $56,45 \%$ dos estudantes afirmaram que antes de realizar uma compra virtual, pesquisam preços e produtos nas lojas físicas. Já para 35,49\% informaram não pesquisar nas lojas físicas antes de comprar. Ainda para $62,26 \%$ dos respondentes declararam ter o costume de comprar na loja virtual a qual também possui a loja física. Por outro lado, 29,68\% informaram não comprar dentro desse parâmetro.

Segundo as informações da pesquisa, o equipamento mais utilizado pelos alunos para compras pela internet é o notebook, que corresponde a $53,87 \%$ do total. Na sequência aparece o computador (desktop) com $24,19 \%$ da preferência, seguido do aparelho smartphone com 13,56\%. O tablet aparece como opção de $0,32 \%$.

Já para identificar a forma de pagamento que os alunos da Instituição utilizam com mais frequência, procurou-se saber de que maneira eles geralmente pagam suas compras virtuais. Conforme resultados apresentados na Tabela 2, 59,35\% dos estudantes utilizam com mais frequência o cartão de crédito como forma de pagamento. Para $31,62 \%$ o boleto bancário é o mais utilizado. O depósito bancário foi citado por $0,65 \%$ do total e $0,32 \%$ utilizam outra forma de pagamento.

Tabela 2 - Forma de pagamento mais utilizado nas compras pela internet

\begin{tabular}{l|c|c}
\hline \multicolumn{1}{c|}{ Forma de pagamento } & $\mathbf{N}^{\mathbf{0}}$ de Citações & \% \\
\hline Cartão de crédito & 184 & 59,35 \\
Boleto bancário & 98 & 31,61 \\
Não compro pela Internet & 25 & 8,07 \\
Depósito bancário & 2 & 0,65 \\
Outra & 1 & 0,32 \\
\hline Total & 310 & 100,00 \\
\hline
\end{tabular}

Fonte: Resultado do levantamento (2017).

Além disso, conforme os respondentes, 47,10\% asseguraram pagar suas compras virtuais a prazo. De acordo com as informações da pesquisa, o aluno que adquire a prazo normalmente parcela essa compra em até 6 vezes, o que representa $46,45 \%$ dos entrevistados. Outros $14,52 \%$ afirmaram que parcelam entre 7 vezes e 12 vezes. Os que parcelam acima de 12 vezes representam 1,61\%. Declararam comprar somente à vista $29,36 \%$ do total de respondentes.

Segundo apuração dos dados da pesquisa, 25,81\% dos entrevistados gastaram até $\mathrm{R} \$ 100,00$ na sua última compra virtual. Para $28,06 \%$ dos 
respondentes gastaram entre $R \$ 101,00$ e $R \$ 200,00$, seguido de $8,39 \%$ que gastaram entre $R \$ 201,00$ e $R \$ 300,00$. Aqueles que informaram terem gasto entre $R \$ 301,00$ e $R \$ 400,00$ representou $5,16 \%$. Os que gastaram entre $R \$ 401,00$ e $\mathrm{R} \$ 500,00$ correspondem à $10,65 \%$, e $13,87 \%$ afirmaram terem gasto outros valores acima desse montante.

Esses resultados estão de acordo com Las Casas (2010), que salienta que todos os produtos ou serviços ofertados no mercado têm como base central o cliente, ou seja, são adquiridos produtos conforme a condição socioeconômica dos clientes.

Conforme resultados apresentados na Tabela 3, foi possível observar qual categoria de produtos é a mais adquirida pelos respondentes. Nota-se que $49,35 \%$ dos respondentes compram roupas, 48,71\% adquire eletrônicos e informática, 25,81\% compram eletrodomésticos e utilidades domésticas, 26,45\% adquirem livros e revistas, CDs, DVDs e Blu-Rays. Outros 24,19\% compram telefonia, 23,55\% adquirem produtos de saúde e beleza, 15,16\% compram produtos relacionados aos esportes, 10,97\% adquirem passeios e viagens. $9,35 \%$ compram produtos de games, $2,90 \%$ adquirem alimentos e bebidas e $7,42 \%$ responderam que adquirem outras categorias de produtos.

Tabela 3 - Categorias de produtos comprados pela internet

\begin{tabular}{l|c|c}
\hline \multicolumn{1}{c|}{ Categoria de produtos } & $\mathbf{N}^{\mathbf{0}}$ de Citações & $\mathbf{\%}$ \\
\hline Roupas & 153 & 49,35 \\
Eletrônicos e Informática & 151 & 48,71 \\
Livros e Revistas; CDs, DVDs e Blu-Rays & 82 & 26,45 \\
Eletrodomésticos e Utilidades domésticas & 80 & 25,81 \\
Telefonia & 75 & 24,19 \\
Saúde e Beleza & 73 & 23,55 \\
Esportes & 47 & 15,16 \\
Passeios e Viagens & 34 & 10,97 \\
Games & 29 & 9,35 \\
Alimentos e Bebidas & 9 & 2,90 \\
Outros & 23 & 7,42 \\
Não compro pela Internet & 25 & 8,07 \\
\hline Total & 781 & - \\
\hline
\end{tabular}

Fonte: Resultado do levantamento (2017). Obs.: O número total de citações é superior ao número de respondentes, haja vista a questão permitir a resposta em mais de uma alternativa.

Conforme os dados da pesquisa aplicada, os entrevistados puderam informar qual o nome da última loja virtual que compraram algum produto. Desses, 15,81\% declararam as Lojas Americanas, 10,65\% o Mercado Livre, $9,03 \%$ a Netshoes, $6,45 \%$ o AliExpress, $4,19 \%$ o Submarino, $3,87 \%$ a Saraiva, $2,58 \%$ o Magazine Luiza. Com 2,26\% cada, são citadas a Dafiti e Ponto Frio. A Kanui aparece com 1,61\% das citações, enquanto as Casas Bahia e a Centauro 
tiveram 1,29\% cada. A Dell, as Lojas Colombo e a Sephora correspondem a 0,97\% cada. As empresas Connect Parts, Enjoei, Extra, FutFanatics, Renner, Ricardo Eletro, Shoptime e Zattini representaram 0,65\% cada. Outras 49 lojas virtuais foram citadas uma vez cada $(0,32 \%)$, e constituem um total de $15,81 \%$. Não responderam essa questão $6,77 \%$ dos alunos.

\subsection{Apresentação de resultados cruzados}

Segundo Solomon (2011), é de extrema importância compreender a idade dos clientes, haja vista que, da mesma faixa etária dividem um conjunto de princípios e experiências em comum, e os de outras faixas etárias exibirem objetivos e necessidades bastante distintas.

Conforme a Tabela 4, é possível observar que o fator preço, de maneira geral, é o principal motivo que levam os estudantes respondentes a adquirirem produtos e serviços pela internet, isso em todas as faixas etárias pesquisadas. A facilidade de compra, a variedade dos produtos e serviços oferecidos, vem respectivamente em segundo e terceiro lugar dos fatores mais relevantes no momento da compra.

Tabela 4 - Idade versus principal fator que leva o estudante a comprar pela internet

\begin{tabular}{|c|c|c|c|c|c|c|c|c|}
\hline Faixa etária & $\begin{array}{l}\text { Agilidade } \\
\text { de entrega }\end{array}$ & $\begin{array}{c}\text { Condições } \\
\text { de } \\
\text { pagamento }\end{array}$ & Confiabilidade & $\begin{array}{l}\text { Facilidade } \\
\text { de compra }\end{array}$ & $\begin{array}{c}\text { Não } \\
\text { compro } \\
\text { pela } \\
\text { internet }\end{array}$ & Preço & Variedade & $\begin{array}{l}\text { Total } \\
\text { Geral }\end{array}$ \\
\hline De 16 a 21 & - & $2,94 \%$ & $0,98 \%$ & $7,84 \%$ & $12,75 \%$ & $58,82 \%$ & $16,67 \%$ & 102 \\
\hline De 22 a 27 & - & $6,35 \%$ & $3,97 \%$ & $11,90 \%$ & $6,35 \%$ & $53,97 \%$ & $17,46 \%$ & 126 \\
\hline De 28 a 33 & - & $16,28 \%$ & - & $25,58 \%$ & $2,33 \%$ & $41,86 \%$ & $13,95 \%$ & 43 \\
\hline De 34 a 39 & $4,35 \%$ & $4,35 \%$ & - & $30,43 \%$ & - & $39,13 \%$ & $21,74 \%$ & 23 \\
\hline $\begin{array}{c}\text { Mais de } 40 \\
\text { anos }\end{array}$ & - & $6,25 \%$ & - & $31,25 \%$ & $18,75 \%$ & $37,50 \%$ & $6,25 \%$ & 16 \\
\hline Total Geral & 1 & 20 & 6 & 46 & 25 & 161 & 51 & 310 \\
\hline
\end{tabular}

Fonte: Resultado do levantamento (2017).

Já de acordo com a Tabela 5, observa-se que, de forma geral, a maioria dos alunos tem remuneração mensal entre dois e três salários mínimos. E a maior parcela que recebe esses valores fica entre a faixa etária de 22 a 27 anos. 
Tabela 5 - Idade versus renda mensal individual

\begin{tabular}{ccccccc}
\hline Faixa etária & $\begin{array}{c}\text { Até 1 } \\
\text { salário } \\
\text { mínimo }\end{array}$ & $\begin{array}{c}\text { Entre } \\
\mathbf{2} \text { a 3 } \\
\text { salários } \\
\text { mínimos }\end{array}$ & $\begin{array}{c}\text { Entre } \\
\mathbf{4} \text { a 6 } \\
\text { salários } \\
\text { mínimos }\end{array}$ & $\begin{array}{c}\text { Entre } \\
\mathbf{7} \text { a 9 } \\
\text { salários } \\
\text { mínimos }\end{array}$ & $\begin{array}{c}\text { Acima } \\
\text { de 10 } \\
\text { salários } \\
\text { mínimos }\end{array}$ & Total Geral \\
\hline De 16 a 21 & $41,18 \%$ & $56,86 \%$ & $0,98 \%$ & - & $0,98 \%$ & 102 \\
De 22 a 27 & $15,08 \%$ & $71,43 \%$ & $12,70 \%$ & $0,79 \%$ & - & 126 \\
De 28 a 33 & $4,65 \%$ & $60,47 \%$ & $30,23 \%$ & $2,33 \%$ & $2,33 \%$ & 43 \\
De 34 a 39 & - & $47,83 \%$ & $30,43 \%$ & $13,04 \%$ & $8,70 \%$ & 23 \\
Mais de 40 anos & $12,50 \%$ & $43,75 \%$ & $12,50 \%$ & $18,75 \%$ & $12,50 \%$ & 16 \\
\hline Total Geral & 65 & 192 & 39 & 8 & 6 & 310 \\
\hline
\end{tabular}

Fonte: Resultado do levantamento (2017).

Conforme a Tabela 6, a maior parte dos respondentes adquire produtos e serviços pelo e-commerce a cada trimestre. Mensalmente, os homens adquirem mais que as mulheres. E ainda existe uma pequena parcela de pessoas que nunca compraram pela internet e pretendem comprar um dia, além dos que nunca compraram e também não tem a pretensão de comprar.

Tabela 6 - Sexo dos respondentes versus frequência de compra pela internet

\begin{tabular}{|c|c|c|c|c|c|c|c|}
\hline Sexo & Semanal & Mensal & Trimestral & Anual & $\begin{array}{c}\text { Nunca } \\
\text { comprou, } \\
\text { mas pretende } \\
\text { comprar um } \\
\text { dia } \\
\end{array}$ & $\begin{array}{c}\text { Nunca } \\
\text { comprou } \\
\text { e não } \\
\text { pretende } \\
\text { comprar }\end{array}$ & $\begin{array}{l}\text { Total } \\
\text { Geral }\end{array}$ \\
\hline Feminino & $3,91 \%$ & $26,26 \%$ & $34,08 \%$ & $25,14 \%$ & $7,82 \%$ & $2,79 \%$ & 179 \\
\hline Masculino & $3,82 \%$ & $39,69 \%$ & $34,35 \%$ & $17,56 \%$ & $4,58 \%$ & - & 131 \\
\hline $\begin{array}{l}\text { Total } \\
\text { Geral }\end{array}$ & 12 & 99 & 106 & 68 & 20 & 5 & 310 \\
\hline
\end{tabular}

Fonte: Resultado do levantamento (2017).

Também foi possível identificar a distribuição das formas de pagamento das compras conforme o sexo dos respondentes. Constatou-se que as mulheres compram mais no boleto bancário do que os homens. Por outro lado, os homens utilizam mais o cartão de crédito para realizar os pagamentos se comparados às mulheres.

\section{CONCLUSÕES}

Essa pesquisa teve como objetivo principal caracterizar o comportamento de compra pela internet, dos alunos da Universidade do Vale do TaquariUnivates. Através de uma pesquisa quantitativa descritiva, respondida por 310 alunos da Instituição e de diferentes cursos, foram obtidos os resultados, sendo esses tabulados e analisados detalhadamente. 
Sobre o perfil dos respondentes, a maioria é representada por mulheres $(57,74 \%)$ e os homens representaram $(42,26 \%)$, com idades entre 22 a 27 anos, com nível superior incompleto, solteiros, sem filhos e com uma renda individual mensal entre dois e três salários mínimos.

O estudo realizado proporcionou observar que o fator principal que leva os alunos a comprarem pela internet é o preço dos produtos e serviços oferecidos. Compram pela internet porque gostam de aproveitar as promoções ofertadas. A maioria realiza pesquisas de preços e produtos nas lojas físicas, antes de efetuar uma aquisição virtual. A maior parte dos estudantes compra em lojas virtuais que também possuem a loja física. E normalmente as compras são realizadas através do notebook.

Constatou-se junto aos entrevistados que a maioria adquire pela internet a cada trimestre, gastando em média entre $R \$ 101,00$ e $R \$ 200,00$ por compra efetuada. Predomina o valor como sendo o motivo decisivo na hora de optar por um determinado produto escolhido.

A pesquisa realizada permitiu conhecer a categoria de produtos mais adquirida pelos acadêmicos respondentes, sendo roupas, eletrônicos e informática as mais citadas. Quanto aos gastos realizados na última compra virtual, a maioria informou ter desembolsado entre $R$ \$ 101,00 e R \$ 200,00. Em relação à última loja que os estudantes adquiriram produtos, as Americanas, $\mathrm{O}$ Mercado Livre e a Netshoes foram as mais mencionadas.

Quanto à forma de pagamento, o cartão de crédito foi o mais citado pelos respondentes. Para a maioria, prevalece o pagamento a prazo e quando realizado dessa maneira, predomina o parcelamento em até 6 vezes.

De maneira geral, o estudo proporcionou ter um maior conhecimento a respeito de comércio eletrônico, especificamente o comportamento de compra virtual de alunos de uma Universidade do Rio Grande do Sul.

\section{REFERÊNCIAS}

ALBERTIN, A. L. Comércio eletrônico: modelo, aspectos e contribuições de sua aplicação. 2. ed. São Paulo: Atlas, 2000.

COBRA, M. Administração de marketing no Brasil. 2 ed. São Paulo: Cobra, 2006.

CORDEIRO, M. B. Marketing de Relacionamento para o Mercado Imobiliário: Um estudo do mercado imobiliário da região central de Florianópolis. Programa de PósGraduação em Engenharia de Produção, Florianópolis, 2006. 164 p. Disponível em: <https:// repositorio.ufsc.br/>. Acesso em: 24 out. 2016.

GIL, A. C. Métodos e técnicas de pesquisa social. 5.ed. São Paulo: Atlas, 2007. 
HOFFMANN, D. L.; NOVAK, T. P. Um novo paradigma de marketing para o comércio eletrônico. In: SHETH, J. N.; ESHGHI, A.; KRISHNAN, B. C. Marketing na internet. Porto Alegre: Bookman, 2002.

KOTLER, P.; KELLER, K. Administração de marketing. 12. Ed. São Paulo: Pearson Prentice Hall, 2006.

LAS CASAS, A. L. Administração de Marketing: conceitos, planejamento e aplicações à realidade brasileira. 1. Ed. São Paulo: Atlas, 2010.

LAUDON, K. C.; LAUDON, J. P. Sistemas de informações gerenciais. 7 ed. São Paulo: Pearson Prentice Hall, 2007.

MALHOTRA, N. Pesquisa de marketing. 3. ed. Porto Alegre: Bookman, 2001.

MALHOTRA, N. K. Pesquisa de marketing: uma orientação aplicada. 4. ed. Porto Alegre: Bookman, 2006.

MARCONI, M. A.; LAKATOS, E. M. Metodologia do Trabalho Científico. Editora Atlas, São Paulo 2001.

MARTINS, P. G.; LAUGENI, F. P. Administração da Produção. Editora Saraiva. São Paulo 2005.

MATTAR, F. N. Pesquisa de marketing. 3.ed. São Paulo: Atlas, 2001.

MATTOS, H.; CUNHA, A. S.; SOARES, T. C. Ambiente virtual: fatores que influenciam na aquisição de bens ou serviços. Revista de Administração da UNIMEP, v.9, n.1, 2011.

MCKENNA, R. Marketing de Relacionamento: estratégias bem-sucedidas para a era do cliente: Rio de Janeiro: Campus, 1992.

ROESCH, S. M. A. Projetos de Estágio e de Pesquisa em Administração. $3^{a}$. Ed. Ed. Atlas, 2005. São Paulo.

RIZZO, E. Uma análise comparativa entre o Marketing de Massa e o One to One Marketing no cenário das empresas competitivas. Revista Mackenzie, São Paulo, 2001.

SHETH, J.N.; MITTAL, B.; NEWMAN, B.I. Comportamento do cliente: indo além do comportamento de do consumidor. São Paulo: Atlas, 2001.

SILVA, L. V. O desenvolvimento do comércio eletrônico no âmbito internacional da convenção internacional de compra e venda de Viena. Dissertação de mestrado. PUCSP. 2016.

SOLOMON, M. R. O Comportamento do consumidor: comprando, possuindo e sendo. 9. ed. Porto Alegre: Bookman, 2011. 
TAPSCOTT, D. A hora da geração digital. Rio de Janeiro: Agir Negócios, 2010.

TERZONI, M. D. E-COMMERCE BRASIL EXCELÊNCIA EM E-COMMERCE. O Facebook-Commerce ou F-commerce. Disponível em: <https:/ /www. ecommercebrasil.com.br/artigos/f-commerce-como-vender-dentro-facebook/>. Acesso em: 18 out. 2016.

TURBAN, E.; KING, D. Comércio eletrônico: estratégia e gestão. São Paulo: Prentice Hall, 2004.

TURBAN, E.; RAINER, R. K.; POTTER, R. E. Administração da tecnologia da informação: teoria e prática. 2. Ed. Rio de Janeiro: Campus, 2003.

VERÍSSIMO, C. Comércio Eletrônico: uma nova viagem ao mundo dos negócios. Sebrae. Disponível em: < http:/ / www.biblioteca.sebrae.com.br/>. Acesso em: 20 out. 2016. 